\title{
Videolaparoscopic Treatment of Meckel's Diverticulum
}

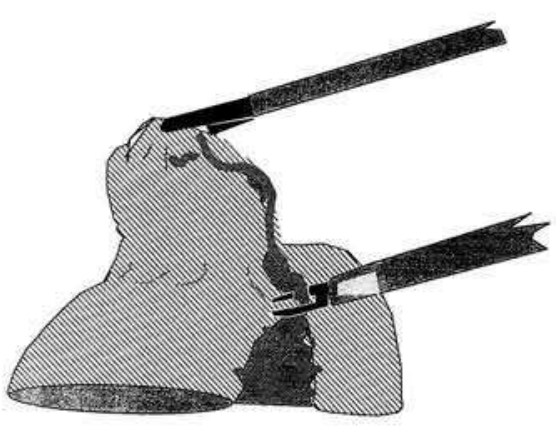

Figure 1: Isolating the base of the diverticulum using sharp dissection and the ENDO-Clip ML TM. Puncture sites for the two trocars are within the umbilicus for the endoscope $(10 \mathrm{~mm})$ and suprapubically for the atraumatic forceps $(5 \mathrm{~mm})$. An additional $12 \mathrm{~mm}$ Surgiport TM trocar is used for the Multifire ENDO-GIA TM.

Small bowel exploration during open appendectomy is a well established procedure $(1,2)$ but it is not mentioned in the relevant laparoscopic literature. The significance of laparoscopic small bowel exploration is shown by the following case report. A 32 year-old female patient presenting with recurrent abdominal pain in the lower right and lower middle abdomen was admitted for laparoscopy. Previous serological tests, gynecological examination and ultrasonography of the abdomen were normal. Laparoscopic appendectomy (3) was followed by small bowel exploration. Thereby a Meckel's diverticulum was detected. The diverticulum was successfully treated using laparoscopic techniques (Figures 1 and 2). No complications occurred intra- and postoperatively. The operation time was 95 minutes and the duration of the hospital stay was four days. The patient showed no further symptoms in a follow-up of seven months. Patsner et al. (4) reported in their study that routine stapler resection of asymptomatic uncomplicated Meckel's diverticulum at the time of extended abdominal gynecologic cancer surgery may also be performed safely and without added morbidity. Ludtke et al. (5) noted that diverticulectomies may be accomplished faster and with less morbidity by simple excision at the base using either a clamp or a stapler. Since a new stapler for endoscopic surgery is now available it can also be used for resection of intestinal lesions, and for precise and adequate diverticulectomy, without additional surgical morbidity.

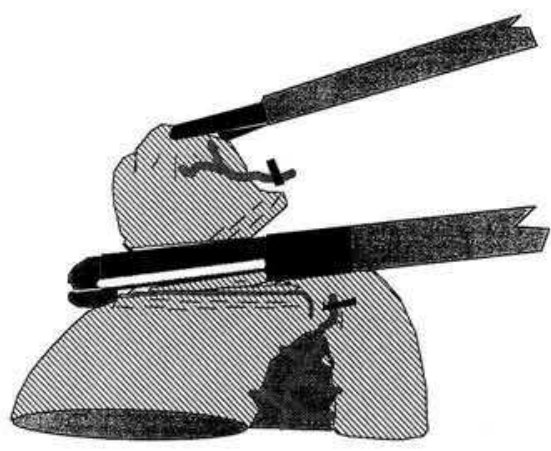

Figure 2: Transresection of Meckel's diverticulum. Activating the Multifire ENDO-GIA TM $30 \mathrm{~mm}$ across the base of the diverticulum at a 45 degree angle to the long axis of the bowel. The resected diverticulum is pulled into the $12 \mathrm{~mm}$ Surgiport TM and removed with the trocar.

\section{K. Miller*, J. Hutter}

Second Surgical Department

Landeskrankenanstalten Salzburg

Müllner-Hauptstr. 48

A-5020 Salzburg, Austria

\section{References}

1. Michas CA, Cohen SE, Wolfmann EF Jr.: Meckel's diverticulum. Should it be excised incidentally at operation? Amer. J. Surg. 1975; 129: $682-685$

2. Soltero MJ, Bill AH: The natural history of Meckel's diverticulum and its relation to incidental removal. Amer. J. Surg. 1976; 132: 168 $-173$.

3. Semm K, Freys I: Endoscopic appendectomy: technical operative steps. Minimally Invasive Therapy 1991; 1: 41-50.

4. Patsner B, Chalas E, Orr JW Jr et al.: Stapler resection of Meckel's diverticulum during gynecologic cancer surgery. Gynecologic Oncology 1990; 38: 179-199.

5. Ludtke FE, Mende $V$, Kohler $H$ et al.:Incidence and frequency of complications and management of Meckel's diverticulum. Surg. Gynecol. Obstet 1989; 169: 537-542. 